inquiry into disease mortality and its changing distribution in England and Wales has now been entitled "Distribution of Health and Location of Industry", and a report on the findings is in preparation. "The British Banking System, 1939-45" will be ready for publication shortly, and the Institute has also been able to assist an inquiry into the influence of social factors on the infant mortality rates in England and Wales before the War. Although the first six months of 1944 constituted the most satisfactory period in the working life of the Library, considerable damage was caused to the material in it by the flying-bomb which wrecked the Institute's premises in July, and most of the material had to be stored.

A separate list of publications and programmes of the Institute dated September 1945 has also been issued. In Sections 1 and 2 of this pamphlet are listed the titles and authors of the books already published or in the press in the two series, Economic and Social Studies and Occasional Papers. Section 3, which gives an account of work in active preparation for the press, contains further information regarding the scope of some of those major research programmes which are sufficiently advanced to permit an account of the series of publications which they are expected to produce.

\section{6 \\ INDIAN ASSOCIATION FOR THE CULTIVATION OF SCIENCE}

\section{ANNUAL REPORT}

$\mathrm{T}$ HE recently issued annual report for the year 1944 of the Inetan Association for the Cultivation of Science, "infwallion to the financial statement and accentrof the various funds and the budget estifot 1 for 1945 , includes a list of papers appearing in four issues of the Indian Journal of Physics and the Proceedings of the Indian Association for the Cultivation of Science published during the year.

A report on the scientific work of the Association by Prof. K. Banerjee is appended, with a list of papers. Detailed studies on the extra reflexions in Laue photographs indicate that these reflexions may be divided into three classes. The first, which has been observed by C. V. Raman and by Lonsdale and Smith for diamond, by C. R. Bose and Prof. Banerjee for phloroglycinol dihydrate and by the latter and R. K. Sen for benzil, shows extremely sharp spots which fall off in intensity very slowly with increase of deviations from the glancing angles for Bragg reflexions. The second type of extra reflexion consists of sharp lines in the Laue photographs and has been closely studied in benzil, where the reciprocal lattice points have plane extensions. The third type is the very commonly studied type of diffuse reflexions. Investigations into the atomic arrangements of some organic crystals, including benzil and phenanthrene, by the method of Fourier analysis, are being made. Other $\mathrm{X}$-ray investigations have covered the solid solutions of metals and salts in glass, indicating that the introduction of gold and platinum induces devitrification, while these metals enter into the glass in fine colloidal states.

The effect of change of wave-length of the exciting radiation on the fluorescence of naphthacene has been studied by exciting a crystal of anthracene containing traces of naphthacene, and it has been shown that the positions and numbers of fluorescence bands do not change with wave-length of exciting radiation. The substance continues to fluoresce even when the wave-length of the exciting radiation is between that of the longest wave absorption band of anthracene and that of naphthacene in that material. It has also been found that the position and number of fluorescence bands of anthracene, perylene, phenanthrene and naphthacene in benzene are independent of the wave-length of the exciting radiation, and the longest wave-length in the absorption spectrum of a substance is its eritical wave-length for excitation of fluorescence; the fluorescence becomes very strong when the exciting radiation lies in any absorption band of the substance.

The effect of solvents on the absorption and fluorescence spectra of naphthacene has also been studied, and Raman spectra of ethylene dibromide, ethylene chlorohydrin, propyl bromide and dichlorethylene have been investigated in the solid phase at the temperature of liquid oxygen as well as in the liquid state. Other investigations have covered the optical anisotropy of organic erystals such as anthracene, $m$-dinitrobenzene, tetrachlornaphthalene and phloroglucinol dihydrate; the magnetic properties of molybdenite crystals ; and the Kerr effect in glass.

$$
\text { HEALTH SURVEY IN INDIA }
$$

THE Singur Health Centre, which is attached to the All India chstitute of Hygiene and Public Health, Calchot, conied out a general health survey of thef Unibus of Singur, Bora, Balarambati and Figan our, a predominantly Hindu area of 33 square mil $\%$ with a total population of 68,000 people, sifuated about 22 miles from Calcutta, during January-August 1944. The report of this survey, which is obtainable from the Institute, is summarized in an article in Science and Culture $(11,489 ; 1945-46)$ by Dr. R. B. Lal, who also addressed the Calcutta Rotary Club in February 1946 on the same subject.

The scientific worker of to-day, said Dr. Lal, is not content to wrest secrets from Nature; he also wants to know why the results of scientific research are not used to improve the lot of those masses of people who still live in a primitive way. Dr. Lal's efforts to establish a well-planned health service in the area surveyed will command the support of all public-spirited people.

The area is much overcrowded. About 65 per cent of the people have less than 36 sq. ft. of floor space and the housing conditions are poor. This probably accounts for the high incidence of hookworm disease, especially among males. Anæmia is a striking feature. The chief causes of death are dysentely, pneumonia, the typhoid fevers and malaria. The survey was carried out in a non-malarial season, but malaria needs special attention. Anopheles philippensis is believed at present to be the only vector of malaria in the area, but other species may also be involved. "The Bengal Famine does not seem to have affected this area in $1943 \ldots$ but evidence of stress was seen later." Less than 50 per cent of the population are between the ages of sixteen and fifty-five, so that the active population includes children and old people. The proportion of active people is, however, low. In India as a whole, 44 per cent of the population contribute to the family income; but in Bengal only 29 per cent do so and in the Singur area 31 per cent; the difference is due to the fact that women in the 
Singur area do not undertake remunerative occupations.

Most of the people are engaged in agriculture; the land is intensively eultivated, but less than 50 per cent of males are engaged in this work. The number of cattle is large in proportion to the population, but most of them are of inferior stock. Nevertheless, many people work in industries and move daily to and from Calcutta, thus creating epidemiological problems. Discussing the economies of the area, Dr. Lal points out that 36 per cent of the 11,700 families in it fail to balance their budget and that 18 per cent of them are in a hopeless economic position. Little is spent on education and, although much is spent by the people on medical care, the loss due to sickness is "colossal". Wastage of life of young children and the retarded growth of children as a whole are serious problems. When a child is one year old in this area it is already one year behind its American brother in weight and half a year behind in height. Malnutrition is one of the main causes of this. Only 10 per cent of children under two receive more than 10 ounces of milk. Other causes are lack of qualified medical men and large numbers of "practitioners of unscientific medicine". Late weaning also contributes, children often not being weaned until the next pregnancy occurs. The outlook on food is mainly determined by tradition, the diet being deficient in fats, calcium and vitamins. Demons are regarded by 27 per cent of the people as the cause of disease and 34 per cent blame God for it.

Dr. Lal concludes that economic prosperity is associated with better health and that the evidence provided by the report does not suggest that education will help to reduce sickness. "Just literates are worse than illiterates." The birth-rate is not likely to be reduced unless there is a check on the marriage-rate and postponement of marriages; but there is at present little hope of these reforms. There is no evidence that alcohol or narcotics play any part on the national loss due to illness.

This careful survey provides many hard facts and much food for thought. It is evident that India need not go beyond her own sons for wise guidance in the reforms that are so urgently needed. G. LAPAGE

\section{6 \\ SOUTH-EASTERN UNION OF SCIENTIFIC SOCIETIES}

\section{JUBILEE CONGRESS}

$\mathrm{T}$ HE jubilee congress of the Union was held at Tunbridge Wells during July 9-13 at the invitation of the Mastor and the Tunbridge Wells Natural History \$d Wdit. The Mayor, Mr. T. C. Allen, in wekdhind the Union to its place of birth, spoke of th 6 tromendous strides made by science during the fity fears since the inception of the Union, but he said that the recent development of the atom bomb made him apprehensive of the future.

The presidential address, delivered by Prof. J. D. Bermal, was entitled "The Place of Scientific Societies in the New World". In outlining the historic development of regional scientific societies, Prof. Bernal spoke of the notable part played by them during the hundred years before the War, but in recent years their work has been overshadowed by that of the great laboratories and institutes. Amateurs often wonder if it is worth while endeavouring to compete with the professional scientific worker, who is pro- vided with the money and man-power which moderm science seems to require. This results in a divoree between science and the public which is to be deplored. There must not be professional scientific workers and a lay public. Everyone must be a scientist for, while common sense can go a long way, scientific decisions are necessary to solve the problems of to-day. The health of science depends upon the interest and service of a large proportion of the population, and local and regional scientific societies are best fitted to organise the collaboration of the public with science. Prof. Bernal said that in operational research the services of people actually employed in operations are necessary to obtain the facts without which scientific analysis would be of no use. The methods used are those of simple statistical survey. As an example, rationing has for the first time in history been done scientifically and not arbitrarily, and the result achieved is shown by comparing the deterioration of health in Great Britain during the First World War with the average increase of health during the Second World War. Again, planning with due respect to the features of the country and the feelings of the inhabitants now replaces ribbon development. The opinion of the housewife is now being sought on domestic matters. No one in the soap trades ever considered the physical and chemical make-up of washing-up soap. It has been sold for the amount of lather it makes, not because it does the work. In solving household prob. lems rather than finding out what people never had, it is necessary to find what they know and what they have experienced, and to draw conclusions therefrom.

No government department, whether of housing, agriculture or health, can act wisely unless it has information got by a widespread net of informants, and the local scientific societies can form such a net. The surveys undertaken by the Union need to be intensified, multiplied and their results effectively used. The scientific societies should link the efforts of the schools, universities, museums and libraries, and the work will be not less interesting and satisfying if it be turned to the service of national welfare.

In addition to the presidential address the following sectional addresses were delivered: "Wealden Ironworking, its Sites and the Products", by E. Yates; "Roman Roads in the Weald", by I. D. Margary ; "The Vegetation of the Wealden Area", by F. Rose; "The Changing Vegetation of Britain", by Prof. W. H. Pearsall ; "Coastal Preservation and Planning", by J. A. Steers; "Life in Medieval Times in a Sussex Manor", by J. E. Ray ; "The Effects of the Weather on Seasonal Responses of Animals and Plants", by Major H. C. Gunton; "Fifty Years of Wealden Geology", by Dr. J. C. M. Given; "Aeolian or Marine ? The Problem of the Folkestone Beds", by R. Casey ; "Charles Darwin's Life at Downe, Kent", by Dr. O. J. R. Howarth (Pedler Lecture of the British Association); "Mammalian Carriers of Infection", by Dr. E. Hindle ; "Land and Freshwater Mollusca of the Tunbridge Wells Area", by Dr. L. B. Langmead; "Some Birds of Norfolk", by I. Murray Thomson.

Excursions were conducted during the afternoons to places of scientific interest within the area.

The presidential and sectional addresses will be published with the transactions in Vol. 51, 1946, of the South-Eastern Naturalist and Antiquary.

The Congress for 1947 will be held at Brighton during the second week in July, the president-elect being Prof. F. Balfour-Browne. 